\title{
COLLOQUE « DU FOLKLORE À L'ETHNOLOGIE. INSTITUTIONS, MUSÉES, IDÉES EN FRANCE ET EN EUROPE DE 1936 À 1945 » MUSÉE NATIONAL DES ARTS ET TRADITIONS POPULAIRES MARS 2003
}

\author{
APPEL À COMMUNICATIONS
}

Depuis plusieurs années les recherches traitant de cette période décisive pour l'éthnologie et le folklore français se multiplient. Il s'agit de faire le point sur ces recherches en portant un regard historique, critique et pluridisciplinaire sur les institutions (et au premier chef le MNATP), les hommes, les débats idéologiques, les cheminements scientifiques et le contexte politique de cette période.

Dans le champ de cette histoire culturelle, on souhaite approfondir la réflexion sur:

- Le folklore : théories, publications et idéologies; organisations, manifestations et activités.

- Régionalismes et culture nationale : courants, mouvements d'idées, partis politiques.

- L'ethnographie : recherche, enseignement, enquêtes et collectes; la construction d'une méthodologie.

- Les rapports entre ethnologie et anthropologie: exotisme, colonialisme, juridisme, biologisme.

- Les expositions et les musées : réflexions et modèles, créations d'établissements.

- Le MNATP : naissance et premières réalisations, constitution des collections et de la documentation, organisation de la recherche, réseaux et partenaires.

- Les loisirs, les mouvements de jeunesse et d'éducation populaire.

- Les notions de culture populaire et de «civilisation traditionnelle».

- Ethnographie, folklore et histoire des sociétés rurales.

- Artisanat, art populaire et création.

Il est également souhaitable de se pencher sur des organismes et institutions aussi divers que la Commission des recherches collectives, la Société du folklore français, la Corporation nationale paysanne, le Service de l'artisanat, la fondation Alexis Carrel, l'Institut celtique de Bretagne... et sur des figures (Arnold Van Gennep, Jean Charles Brun, Paul Rivet, Georges Henri Rivière, Marcel Maget, André Varagnac, Pierre-Louis Duchartre, Guy Pison, Louis Dumont, André Leroi Gourhan, René Maunier, André Dauzat, les enquêteurs des chantiers, Albert Soboul, Jean Amblard, les conservateurs des musées, les érudits, les folkloristes locaux...)

L'étude des fonds d'archives conservés au service historique du MNATP est aujourd'hui facilitée par la réalisation récente d'instruments de recherche (liste de dossiers, inventaires sommaires et détaillés, répertoires).

Les propositions de communications (au maximum 1 page) devront être adressées à l'attention de Michel Colardelle, directeur du MNATP, colloque «Du folklore à l'ethnologie », Musée national des arts et traditions populaires, 6, avenue du Mahatma-Gandhi, 75116 Paris, avant la fin du mois d'avril 2002.

Revue de synthèse : $4^{\mathrm{e}}$ sér., $\mathrm{n}^{\mathrm{os}}$ 2-3-4, avr.-déc. 2001, p. 722. 